\title{
Factors Associated with Cesarean Birth among Infants in the North-East Haut Katanga/DR Congo
}

\author{
Patrick Mubinda Kiopin1, Criss Koba Mjumbe ${ }^{2 *}$, Isango Idi1, Tamubangu Herman3, \\ Albert Mwembo Ntambwe ${ }^{1,2}$, Kakoma Sakatolo Zambeze ${ }^{1,2}$ \\ ${ }^{1}$ Department of Gynecology and Obstetrics, Faculty of Medicine, University of Lubumbashi, Lubumbashi City, \\ Democratic Republic of Congo \\ ${ }^{2}$ Department of Public Health, Faculty of Medicine, University of Lubumbashi, Lubumbashi City, Democratic Republic of Congo \\ ${ }^{3}$ Department of Pediatrics, Faculty of Medicine, University of Lubumbashi, Lubumbashi City, Democratic Republic of Congo \\ Email: *cryss_koba25@yahoo.fr
}

How to cite this paper: Kiopin, P.M., Mjumbe, C.K., Idi, I., Herman, T., Ntambwe, A.M. and Zambeze, K.S. (2020) Factors Associated with Cesarean Birth among Infants in the North-East Haut Katanga/DR Congo. Open Access Library Journal, 7: e6725.

https://doi.org/10.4236/oalib.1106725

Received: August 19, 2020

Accepted: October 25, 2020

Published: October 28, 2020

Copyright (๑) 2020 by author(s) and Open Access Library Inc.

This work is licensed under the Creative Commons Attribution International License (CC BY 4.0).

http://creativecommons.org/licenses/by/4.0/

\section{(c) (i) Open Access}

\begin{abstract}
It is not always easy for a clinician to give a prognosis on a pregnancy diagnosed in a young woman because this profile has a very high morbidity before, during and after childbirth. The objective of this study is to describe the factors associated with adolescent cesarean delivery. This is a descriptive cross-sectional study with an analytical component over a period of 7 months, from February 2017 to August 2017 in the Kilwa Kasenga and Kashobwe health zones. We collected 332 parturients. The analyses were carried out with SPSS 20.0 software with a significance level $\mathrm{p}<0.05$ at $95 \%$ confidence interval. The overall objective of this study is to contribute to the improvement of knowledge about the factors associated with cesarean section among young women in the Northeast of Upper Katanga. During pregnancy, malaria was the most pathology encountered in $35.08 \%$ of cases; mean gestational age at birth was $38 \pm 2$ week of amenorrhea (WA) with as extreme 25 and 43 (WA); the clinical evaluation 34 women in labor or $10.24 \%$ were contracted pelvis and a limited pool in $22.59 \%$ of cases. In $26.81 \%$ of cases, delivery was made by cesarean section; When modeling, uterine height $>34 \mathrm{~cm}$, the breech and the intake guide (evacuated) were significantly associated with caesarean delivery in adolescents with respective Odds Ratio of 10.11 (CI: 2.46 to 41.40 ); 10.11 (CI: $-37.59-2.71$ ) and 21.21 (CI: 5.43 - 82.79), and exposed teenage respectively $10.11 ; 10.11$ and 21.21 times the caesarean sections. Adolescent birth is a serious morbidity; it must attract the attention of the clinician in a teenager referred with a significant uterine fundus, a pathological assessment of the pelvis.
\end{abstract}

\section{Subject Areas}

Gynecology \& Obstetrics 


\section{Keywords}

Factors Associated, Cesarean Birth, Infants, North-East Haut Katanga

\section{Introduction}

The tragedy of maternal mortality remains a scourge that strikes hard on our developing countries, particularly Africa, where socio-economic, environmental and health conditions are very precarious, exposing women to the daunting complications of pregnancy and childbirth [1]. According to the most recent figures from the World Health Organization, 529,000 women die each year from maternal causes and about 50 million women are victims of complications related to pregnancy and childbirth [2]. So thousands of women around the world are living the birth of a child not as the happy event that it should be, but as a test that can even cost them life [3]. In Cameroon, deliveries among adolescents represented $26.56 \%$ of 12,537 deliveries at the maternity hospital of the provincial hospital of Maroua: 7.87\% of deliveries were observed among adolescents 16 years and under and $18.95 \%$ among those from 17 to 19 years old [4]. In South Africa, authors have found that one in four women in childbirth is under the age of 20 [4]. In the DRC, EDS RDC 2014 found that more than a quarter of adolescent girls (27\%) had already started their fertile life, $21 \%$ had had at least one child and 6\% were pregnant with a first child. Compared to the first DHS in the DRC, the proportion of adolescent girls who started their fertile life increased slightly, from $24 \%$ in 2007 to $27 \%$ in 2013-2014. This proportion is much higher in rural areas (32\%) than in urban areas (20\%) [5]. These pregnancies present increased risks for the health of the mother and the child, it acts of an increased risk of health problems such as anemia, high blood pressure, eclampsia and depressive disorders in the mother [6]. In the People's Republic of Benin, an author finds a high rate of $5.03 \%$ of toxemia, prematurity, and fetal-pelvic disproportion in primiparas aged sixteen and under [7]. In Côte d'Ivoire, a study on the outcome of pregnancy in adolescents aged 12 to 16 found a high rate of 5.5\% of pre-eclampsia, prematurity, fetal hypotrophy and cesarean section [8] [9]. At the CHU of Yaoundé, it appears that the occurrence of a first childbirth during adolescence was associated with a high risk of prematurity, torn perineum, fetal distress, use of episiotomy, use of oxytocin, cesarean delivery and birth [10]. In developing countries in particular, morbidity and mortality are an immense tragedy that has long been ignored by policymakers. The African continent is the most affected or the risk is sometimes 100 times higher than in the industrialized countries. The maternal mortality rate ranges from 830 per 100,000 live births in African countries to 24 per 100,000 live births in European countries [11]. In summary, studies of these adolescent girls have shown particularly in young people under the age of 19 a very high risk of cesarean delivery and stillbirth. This can be attributed not only to the gynecological immaturity but also to the 
anatomical conditions linked to the pelvis determining a greater occurrence of cephalopelvic disproportion.

The overall objective of this study is to contribute to the improvement of knowledge about the factors associated with cesarean section among young women in the Northeast of Upper Katanga.

\section{Topics and Methods}

\section{Sites and study population}

A cross-sectional descriptive study was carried out in northeastern Upper Katanga in the Democratic Republic of Congo (DRC) in 3 health zones of Kilwa, Kasenga and Kashobwe. The study was conducted from February to August 2017 or 7 months in the Upper Katanga, DRC. We collected 332 pregnant women from the health zones of Kilwa, Kasenga and Kashobwe, all pregnant teenagers aged between 10 and 19 who had come for delivery in the maternity hospitals of the so-called HGRs and living respectively in these health zones.

\section{Data Collection and Parameters of study variables}

Regarding our study, the information on the pregnancies was drawn on the partograph, the consultation sheets in addition we used the delivery record associated with the structured interview. For the study parameters: the socio-demographic parameters: Age, Anthropometry, Level of education, Marital status, Parity, Gestity. The clinical parameters to arrive at its realization. In our study we are more based on clinical parameters to achieve its realization. For the clinical elements, the Mode of admission in the delivery room, the age of pregnancy calculated from that of the last rules declared by the parturient, grouped in prematurity (<38 AS), term pregnancy (38 - $42 \mathrm{SA})$, post-term pregnancy (42 $\mathrm{SA})$. The basin state is normal, limited and narrowed. For narrowed and bounds the promonto retro pubic (PRP) was calculated to be either 10.5 to $9.5 \mathrm{~cm}$ for the limit and $<9.5 \mathrm{~cm}$ narrowed or surgical. The delivery route is laparotomy extraction (caesarean) or natural low pathway.

\section{Ethics authorization}

Consent was obtained from parturients after having been informed about the progress of the study. The study was approved by the Medical Ethics Committee of the University of Lubumbashi.

\section{Statistical analyzes}

The data encoding was done using the Epi Info 7.2 software and the latter were analyzed using the SPSS 23.0 software. Qualitative data were presented as absolute and relative frequencies. For quantitative data except for absolute and relative frequencies, the position indices (mean and median) and dispersions (standard deviation, quartile) were added. Similarly, to test the normality of the latter, the Kolmogorov-Smirnov test was used. Quantitative variables were dichotomized for use in mathematical modeling. We searched for intergroup associations using the Pearson chi-square test and for values less than 5 we used the exact Fischer test. An adjustment was made by stepwise binary logistic regres- 
sion according to the ascending Wald method and any variable with $\mathrm{p}<0.05$ was introduced into the model and the confidence interval was $95 \%$.

\section{Results}

\section{Socio-demographic parameters}

The prevalence of adolescent women in our study was (14.00\%). More than half of the parturients in our study, that is $(69.28 \%)$ were over 15 years of age while in $(30.72 \%)$ they were under 15 years of age. The average is $16 \pm 1$ years with 13 and 19 years as extremes. In relation to the level of education and marital status, about 7 in 10 parturients (68.98\%) were illiterate (32.53\%) or had a level of primary education (36.45\%); similarly, about 7 in 10 parturients $(68,67 \%)$ were single while only 3 in 10 (30.72\%) were married. Regarding obstetric identity, more than three quarters of parturients $(76.20 \%)$ were nulliparous; however, almost a quarter of them (23.80\%) had already had a maternity or more; $(65 \%)$ of parturients were in their first pregnancy, while (34.64\%) had already had one or more pregnancies. More than half of the parturients $(57.53 \%)$ had followed the ANC and, in (73.49\%) of the cases, the parturient had not performed the ultrasound and that only (32.95\%) performed early (Table 1).

As shown in Table 1, pregnancy at ages $<15$ exhibited 4 times at cesarean section as at vaginal delivery with highly significant statistical difference, (OR: 3.66 [1.32 - 10.24]) and sizes $<150 \mathrm{~cm}$ at 3 cesarean section as the low pathway with a highly significant statistical difference, (OR: 3.48 [1.18 - 10.18]).

Table 1. Factors associated with teenage delivery.

\begin{tabular}{|c|c|c|c|c|}
\hline \multirow{2}{*}{ variables } & \multicolumn{2}{|c|}{ Delivery route } & \multirow{2}{*}{ OR [IC 95\%] } & \multirow{2}{*}{$\mathrm{p}$} \\
\hline & high & Low & & \\
\hline Age group (year) & $\mathrm{N}=21$ & $\mathrm{~N}=256$ & & \\
\hline$<15$ & $9(13.60 \%)$ & $63(86.40 \%)$ & $4.04[1.44-11.29]$ & 0.004 \\
\hline$\geq 15$ & $7(3.41 \%)$ & $198(96.59 \%)$ & 1 & \\
\hline \multicolumn{5}{|l|}{ Slice size $(\mathrm{cm})$} \\
\hline$<150$ & $7(16.27 \%)$ & $36(83.87 \%)$ & $3.94[1.14-10.83]$ & 0.004 \\
\hline$\geq 150$ & $11(4.70 \%)$ & $223(95.30 \%)$ & 1 & \\
\hline \multicolumn{5}{|c|}{ History of caesarean section 2} \\
\hline Yes & $2(10.52 \%)$ & $17(92.51 \%)$ & $2.94[0.59-14.60]$ & 0.19 \\
\hline No & $15(5.80 \%)$ & $227(94.20 \%)$ & 1 & \\
\hline \multicolumn{5}{|c|}{ Number of NPCs followed } \\
\hline$<4$ & $13(7.10 \%)$ & $170(92.90 \%)$ & $1.73[0.47-6.27]$ & 0.56 \\
\hline$\geq 4$ & $3(4.20 \%)$ & $68(95.80 \%)$ & 1 & \\
\hline Other gestures & $6(6.30 \%)$ & $89(93.70 \%)$ & $1.00[0.35-2.85]$ & \\
\hline Gravida & $10(6.30 \%)$ & $149(93.70 \%)$ & 1 & 0.99 \\
\hline
\end{tabular}


As shown in Table 2, the fact of being referred exposes adolescent girls to cesarean section 17 times with a highly significant statistical difference (OR 17.22 [5.69 - 52.09]); the uterine height $>34$ to 4 times, with a highly significant statistical difference (OR $4.06[1.45-11.39]$ ), the presentation sits at 11 times with a highly significant statistical difference (OR 10.90 [3.69 - 32.15]), tinted amniotic fluid was 7 times the chance to deliver by caesarean section with a highly significant statistical difference (OR 6.56 [2.30 - 18.66]) and finally a pathological pelvis 4 times the chance to deliver by caesarean section with a highly significant statistical difference (OR 3.63 [1.07 - 12.31]).

As shown in Table 3, Uterine height $>34 \mathrm{~cm}$, seated presentation, and mode of admission (referred) were significantly associated with cesarean delivery in adolescents with adjusted odds ratios of [12.21 (CI: 2.46). 41, 40)]; [10.11 (CI: 2.71 - 37.59)] and [21.21 (CI: 5.43 - 82.79)], and exposed adolescent girls to cesarean section in [10.11 and 21.21 times].

Table 2. Factors associated with teenage delivery (2).

\begin{tabular}{|c|c|c|c|c|}
\hline \multirow{2}{*}{ Variables } & \multicolumn{2}{|c|}{ Delivery route } & \multirow{2}{*}{ OR [IC 95\%] } & \multirow{2}{*}{$\mathrm{P}$} \\
\hline & high & Low & & \\
\hline Mode of admission & $(\mathrm{n}=16)$ & $(\mathrm{n}=238)$ & & \\
\hline Referred & $10(32.30 \%)$ & $21(67.70 \%)$ & $17.22[5.69-52.09]$ & $<0.0001$ \\
\hline Coming from herself & $6(2.70 \%)$ & $217(97.30 \%)$ & 1 & \\
\hline \multicolumn{5}{|l|}{ Uterine height in $\mathrm{cm}$} \\
\hline$>34$ & $8(14.50 \%)$ & $47(85.50 \%)$ & 4.06 [1.45 - 11.39] & $<0.004$ \\
\hline$\leq 34$ & $8(4.00 \%)$ & $191(96.00 \%)$ & 1 & \\
\hline \multicolumn{5}{|l|}{ Presentation } \\
\hline Seat & $8(28.60 \%)$ & $20(71.40 \%)$ & $10.90[3.69-32.15]$ & $<0.0001$ \\
\hline Cephalic vertex & $8(3.50 \%)$ & $218(96.50 \%)$ & 1 & \\
\hline \multicolumn{5}{|l|}{ Amniotic liquid } \\
\hline Not clear & $9(18.80 \%)$ & $39(81.20 \%)$ & $6.56[2.30-18.66]$ & $<0.000$ \\
\hline Clear & $7(3.40 \%)$ & $199(96.60 \%)$ & 1 & \\
\hline \multicolumn{5}{|l|}{ State of the basin } \\
\hline Pathological & $4(16.70 \%)$ & $20(83.30 \%)$ & $3.63[1.07-12.31]$ & $<0.02$ \\
\hline Normal & $12(5.20 \%)$ & $218(94.80 \%)$ & 1 & \\
\hline \multicolumn{5}{|l|}{ Breaking mode } \\
\hline At work & $1(4.30 \%)$ & $22(95.70 \%)$ & $0.65[0.08-5.19]$ & 1.00 \\
\hline Out of work & $15(6.50 \%)$ & $216(93.50 \%)$ & 1 & \\
\hline \multicolumn{5}{|l|}{ Uterine contraction } \\
\hline No & $0(0.00 \%)$ & $7(100.00 \%)$ & & 0.48 \\
\hline Yes & $16(6.50 \%)$ & $231(93.50 \%)$ & & \\
\hline \multicolumn{5}{|l|}{ Working time } \\
\hline$<11$ & $13(6.00 \%)$ & $202(94.00 \%)$ & $0.77[0.21-2.84]$ & 0.45 \\
\hline$>11$ & $3(7.70 \%)$ & $36(92.30 \%)$ & 1 & \\
\hline
\end{tabular}


Table 3. Adjusted variables exposing the adolescent to cesarean section.

\begin{tabular}{ccccc}
\hline \multirow{2}{*}{ Variables } & & \multicolumn{2}{c}{ IC 95\% } & P \\
\cline { 3 - 5 } & ORa & Inferior & superior & \\
\hline Uterine height $(>34 \mathrm{~cm}$ vs $\leq 34 \mathrm{~cm})(\times 1)$ & 12.21 & 2.46 & 41.40 & $<0.0001$ \\
Presentation (cephalic vs summit seat) $(\times 2)$ & 10.11 & 2.71 & 37.59 & $<0.0001$ \\
Admission Mode (Referred vs. Self Coming) $(\times 3)$ & 21.21 & 5.43 & 82.79 & $<0.0001$ \\
\hline
\end{tabular}

\section{Discussion}

Of all the deliveries encountered during our study period, adolescent delivery was $14 \%$. Some studies carried out elsewhere have reported low frequencies, such as those of Lerner in Latin America (0.6\%), Hamada in Morocco (2.6\%), Iloki in Brazzaville (5.3\%) and Kakudji in Lubumbashi in 2017 (7.7\%) [36.46 48]. On the other hand, our prevalence was similar to the study carried out in urban areas by Tambwe in Lubumbashi in 1999 [9] which was 13.9\%. Our results were also superimposable on those of the WHO which reports that teenage motherhood is more common in developing countries where the proportion of women mothers before the age of 18 often reaches 11\% [12]. Our frequency is higher compared to several authors mentioned above because of our larger sample of the methodology used but also because the health zones of Kilwa, Kasenga and Kashobwe being rural areas, we believe that the occurrence of a Pregnancy in adolescence is more common in young people who come from a disadvantaged socio-economic background. Our study shows that the majority of our parturients were over 15 years of age with an average age of $16 \pm 1$ years (69.28\%). The average age is around 15 years; this age is described by several authors as being the pivotal age for physical maturity by ricochet the development of the pelvis. In addition, on the social level, it is an age of curiosity, great tremors which requires support via the various support platforms for the family, the school, the church, etc. Special observations have been made by different authors during this age such as Voltzenlogel à Renne in 2014 [13] who reported that it is around the age of 15 that there are many terminated pregnancies. For Alouini in France in 2015 [14] meanwhile, they were premature deliveries and obstructed labor. Other authors cited by Fatouma in Bamako, described the increased risk of anemia and malformed newborns [12]. For our part, in view of the above, giving birth at this age in our environment could be explained on the one hand by 1) the lack of knowledge about the risk run by parturients who, generally have little weight in decisions that affect their fertility; and their prospects for education or professional training are limited [15] 2) the precociousness of sexual activity which depends on a number of biological, cultural, and religious factors and the age of menarche. 3) Finally, the age of marriage and the tolerance of society for sexual relations before marriage.

In our series, age $<15$ years and height $<150 \mathrm{~cm}$ were statistically related to high birth with odds of 3.66 [1.32 - 10.24], respectively; 3.48 [1.18 to 10.18]. According to the WHO, adolescent girls aged 10 - 14 had a high birth rate in $43.3 \%$ 
which was statistically significant compared to adolescent girls aged 15 - 18 (32.5\%) [5]. This is consistent with the studies of Henry Galardo who reported that the adolescent under 15 was associated with a higher risk of caesarean section with OR 1.3 [1.14 - 1.51] [6]. And the Malabarey study that suggested an increased rate of caesarean section especially among teenagers under 15 years of age [7]. In contrast to Wermoux, who found no signifi- cance between the Caesarized aged under 15 years and that of older age, thus reporting a frequency of $11 \%$ [8]. In addition, Zeteroglu has shown that the biology factors associated with high birth are low weight, small size and parity. We believe that age below 15 would be subject to adverse outcomes due to biological immaturity [9]. Our study also showed that the "coming from" admission mode, the "seat" presentation, the "unclear" amniotic fluid, and the "pathological" pelvis were statistically related to high birth delivery. And after adjustment, it was observed that the hauteur $34 \mathrm{~cm}$ uterine height, seat presentation, and admission pattern were significantly associated with cesarean delivery in adolescents with respective odds ratios of 12.21 (CI: 2.46 - 41.40); 10.11 (CI: 2.71 - 37.59) and 21.21 (CI: 5.43 82.79). Alouini reported that the indications for caesarean section in adolescents were abnormal fetal heart rate (six cases out of 14), maternal pathology (five cases), mechanical dystocia (two cases) and stagnation of dilatation [10]. The BACCI study in Mozambique found that the main indication for caesarean section among adolescent girls was dystocia 41\% [11] [13] [14] for all operations performed in these women, followed by pain and hypertension [12] [15]. Studies in the United States and Turkey have reported that caesarean delivery between teenage girls has been more indicated for hypertensive disease (ORa $=1.34,95 \%$ $\mathrm{CI}=1.02-1.77)[16]$ and for pelvic fooper disproportion, $(\mathrm{ORa}=1.76, \mathrm{CI}$ $1.237 \%-2.51395 \%)$ [12]. In the context like this; in a teenager who is free from all indications of cesarean section, with excessive reference and/or uterine height and/or podalic presentation, the potential for cesarean section is no less.

\section{Conclusion}

In view of the results of our study, it is important to note that childbirth in adolescents is a serious morbidity, it must attract the attention of the clinician in an adolescent girl referred with a significant uterine background, a pathological appreciation of the pelvis. When modeling; uterine height $>34 \mathrm{~cm}$, breech presentation and "referral" mode of admission were significantly associated with cesarean delivery in adolescents.

\section{Acknowledgements}

They are addressed to all authors who contributed to the study at the Ministry of Health of Upper Katanga who supported part of this study.

\section{Contributions of the Authors}

MKP and KSZ designed the study. KMC, II, TH and MNA analyzed the data and 
all the authors discussed the results. They all commented and approved the final version of the article.

\section{Conflicts of Interest}

The authors declare no conflicts of interest regarding the publication of this paper.

\section{References}

[1] WHO (2012) Early Marriages, Teenage Pregnancies and Young Women. Sixty-Fifth World Health Assembly. Report No. A65/13.

[2] Alouini, S., Randriambololona, D. and Randriamboavonjy, R. (2015) Risk Factors of Pregnancy, Childbirth and Postpartum Adolescence in the Loiret Department. Journal de Gynécologie Obstétrique et Biologie de la Reproduction, 44, 443-450. https://doi.org/10.1016/j.jgyn.2014.07.004

[3] Gallardo-Lizarazo, H.R., Guerrero-Romero, I.S., Niño-Gonzalez, J.E. and Villaveces-Franco, M. (2015) Maternity in Adolescents and Its Association with Caesarean Labor. Revista Ciencia y Cuidado, 12, 11-25. https://doi.org/10.22463/17949831.506

[4] Malabarey, O.T., Balayla, J. and Abenhaim, H.A. (2012) The Effect of Pelvic Size on Cesarean Delivery Rates: Using Teenager Maternal Age as an Unbiased Proxy for Pelvic Size. Journal of Pediatric \& Adolescent Gynecology, 25, 190-194. https://doi.org/10.1016/j.jpag.2012.01.002

[5] Wemaux-Denis, C., Garabedian, C., Huc, A., Cailleret, O., Depoortere, M.-H., Hammou, Y., et al. (2017) Pregnancy and Delivery of the Adolescent: Is the Obstetric Prognosis More Unfavorable between 13 and 15 Years? Gynécologie Obstétrique Fertilité \& Sénologie, 45, 5-8. https://doi.org/10.1016/j.gofs.2016.12.007

[6] Zeteroglu, S., Sahin, I. and Gol, K. (2005) Cesarean Delivery Rates in Adolescent Pregnancy. The European Journal of Contraception \& Reproductive Health Care, 10, 119-122. https://doi.org/10.1080/13625180500131600

[7] Bacci, A., Manhica, G.M., Machungo, F., Bugalho, A. and Cuttini, M. (1993) Outcome of Adolescent Pregnancy in Maputo, Mozambique. International Journal of Gynecology \& Obstetrics, 40, 19-23. https://doi.org/10.1016/0020-7292(93)90767-Q

[8] Kawakita, T., Wilson, K., Grantz, K.L., Landy, H.J., Huang, C.-C. and Gomez-Lobo, V. (2016) Maternal Adverse and Neonatal Outcomes in Adolescent Pregnancy. Journal of Pediatric \& Adolescent Gynecology, 29, 130-136. https://doi.org/10.1016/j.jpag.2015.08.006

[9] Ersoy, A.O., Ozler, S., Oztas, E., Ersoy, E., Kirbas, A. and Danisman, N. (2016) The Association between Placenta Previa and Leukocyte and Platelet Indices-A Case Control Study. Ginekologia Polska, 87, 367-371. https://doi.org/10.5603/GP.2016.0006

[10] Bohossou, K.M., Traore, S., Sangaret, M. and Djanhan, Y. (1992) Pregnancy and Adolescence. Afr Med., 21, 359-362.

[11] Kearney, M.S. and Levine, P.B. (2007) Socioeconomic Disadvantage and Early Childbearing [Internet]. National Bureau of Economic Research, Report No.: 13436. http://www.nber.org/papers/w13436 https://doi.org/10.3386/w13436

[12] Koba Mjumbe, C., Kasongo Omba, I., Kabyla Ilunga, B. and Luboya Nuymbi, O. (2020) Problem of the Management of Haemorrhagic Fevers: Experience of Ebola 
Virus Disease in the Province of North Kivu and Ituri (DR Congo) and the Importance of Early Diagnosis. Open Access Library Journal, 7, 1-4.

https://doi.org/10.4236/oalib.1106135

[13] Luong, M. (2008) What Have Become of Teenage Mothers? Perspectives on Employment and Income. Canadian Statistics, 6-13.

[14] East, P.L., Reyes, B.T. and Horn, E.J. (2007) Association between Adolescent Pregnancy and Family History of Teenage Births. Perspectives on Sexual and Reproductive Health, 39, 108-115. https://doi.org/10.1363/3910807

[15] Vinatier, D. (1997) General Information about Pregnancy and Childbirth in Adolescents. EncyclMed Chir, Paris, 1-5. (Obstetrics).

[16] Otterblad Olausson, P.M., Cnattingius, S. and Goldenberg, R.L. (1997) Determinants of Poor Pregnancy among Teenagers in Sweden. Obstetrics \& Gynecology, 89, 451-457. https://doi.org/10.1097/00006250-199703000-00027 